\title{
Volatile Flavor Components of Dried Bonito (Katsuobushi) II. From Neutral Fraction
}

\author{
Izumi YaJima, Mikio NaKamura, Hidemasa SaKaKibara, \\ Junichi Ide, Tetsuya YanaI and Kazuo Hayashi \\ Kawasaki Research Laboratories, T. Hasegawa Co. Ltd., \\ 335-Kariyado, Nakahara-ku, Kawasaki 211, Japan
}

Received October 22, 1982

\begin{abstract}
The aqueous extract of dried bonito (Katsuobushi) was distilled under reduced pressure. The resulting distillate with diethyl ether and the extract was separated into acidic, phenolic, basic and neutral fractions. The neutral fraction was further fractionated into ten sub-fractions by silica gel column chromatography. All these sub-fractions were analyzed by gas chromatography and gas chromatography-mass spectrometry.

One hundred and sixty-five compounds were identified and 12 compounds were tentatively identified from the neutral fraction. Among them, 111 compounds were newly identified as flavor components of Katsuobushi.
\end{abstract}

In a previous paper, ${ }^{1)}$ we have reported on 74 flavor components being identified from the acidic, phenolic and basic fractions obtained from the aqueous extract of dried bonito (Katsuobushi). The paper also showed that the characteristic smoky aroma of Katsuobushi was considered to be made up from a combination of various phenolic compounds found in the phenolic fraction.

The present study was conducted to identify the volatile flavor components in the neutral fraction.

\section{MATERIALS AND METHODS}

Materials. Katsuobushi, produced in the Makurazaki district of Kagoshima Prefecture in Japan, was used immediately after shaving.

\section{Methods.}

a) Collection of volatile flavor compounds. Twenty kilograms of Katsuobushi shaving were added to 300 liters of boiling water, the following procedures for collection of the volatiles being the same as described in the previous paper. ${ }^{1)}$

From the resulting flavor concentrate which had the characteristic flavor of Katsuobushi, $200 \mathrm{ml}$ were further concentrated to about $0.2 \mathrm{ml}$ for gas chromatographic analysis, and the remaining $1800 \mathrm{ml}$ were separated into the acidic, phenolic, basic, and neutral fractions by the methods described in the previous paper. ${ }^{1)}$

Each fraction was concentrated to about $0.1 \mathrm{ml}$, $0.5 \mathrm{ml}, 0.1 \mathrm{ml}$, and $0.5 \mathrm{ml}$, respectively.

b) Fractionation and identification of the neutral fraction. The neutral fraction was further fractionated into ten sub-fractions by silica gel column chromatography. The neutral fraction concentrate was placed on a column $(1 \mathrm{~cm} \times 20 \mathrm{~cm})$ packed with silica gel and successively eluted with mixtures of $n$-pentane and diethyl ether, as shown in Table I.

Each eluted sub-fraction was concentrated to about $0.1 \mathrm{ml}$. Identification of the flavor compounds was made by gas chromatography (GC) and gas chromatography-

Table I. Solvent System Used for Column Chromatography and Percentages of Each Sub-Fraction in the Neutral Fraction

\begin{tabular}{|c|c|c|c|}
\hline \multirow{2}{*}{$\begin{array}{c}\text { Sub-fraction } \\
\text { No. }\end{array}$} & \multicolumn{2}{|r|}{ Solvents } & \multirow{2}{*}{$\begin{array}{l}\% \text { in neutral } \\
\text { fraction }\end{array}$} \\
\hline & $\mathrm{ml}$ & $\begin{array}{c}\text { Ratios of } n \text {-pentane } \\
\text { to ether }(\mathrm{v} / \mathrm{v})\end{array}$ & \\
\hline 1 & 72 & $100: 0$ & 12 \\
\hline 2 & 72 & $98: 2$ & 19 \\
\hline 3 & 72 & $97: 3$ & 15 \\
\hline 4 & 72 & $95: 5$ & 24 \\
\hline 5 & 72 & $93: 7$ & 12 \\
\hline 6 & 72 & $90: 10$ & 8 \\
\hline 7 & 72 & $80: 20$ & 9 \\
\hline 8 & 72 & $50: 50$ & 1 \\
\hline 9 & 72 & $0: 100$ & 0 \\
\hline 10 & 72 & Methanol & 0 \\
\hline
\end{tabular}


mass spectrometry (GC-MS).

c) Conditions of GC. A Hewlett Packard Model 5730A gas chromatograph, equipped with an effluent splitter which was placed between the end of the GC column and three detectors, was used. The effluent was separated into three portions by the splitter at a splitting ratio of $1: 1: 2$, the first portion being passed to a flame ionization detector (FID) circuit, the second to a flame thermionic detector (FTD) circuit and the third to a flame photometric detector (FPD) circuit. A glass SCOT column $(0.5 \mathrm{~mm}$ i.d. $\times 50 \mathrm{~m}$ ) coated with PEG $20 \mathrm{M}$ was used. Other operating conditions were: injection port and detector temperatures, $250^{\circ} \mathrm{C}$; column temperature, programmed from $70^{\circ}$ to $190^{\circ} \mathrm{C}$ at $2^{\circ} \mathrm{C} / \mathrm{min}$; carrier gas $\left(\mathrm{N}_{2}\right)$ flow, $1 \mathrm{ml} / \mathrm{min}$.

d) Sniffing evaluation of flavor compounds emitted at each peak on the gas chromatogram. Sensory evaluation was accomplished by sniffing at the exit port of Hitachi Model 163 gas chromatograph fitted with an effluent splitter, while the samples were being eluted. The detailed conditions for sniffing were the same as described in the previous paper. ${ }^{1)}$

e) Conditions of $G C$-MS. The GC-MS conditions were the same as described in the previous paper ${ }^{1)}$ except that the column temperature was programmed from $60^{\circ} \mathrm{C}$ to $200^{\circ} \mathrm{C}$ at $2^{\circ} \mathrm{C} / \mathrm{min}$.

\section{RESULTS AND DISCUSSION}

The neutral fraction, amounting to about $46 \%$ of the whole flavor concentrate obtained from the aqueous extract of Katsuobushi, had a somewhat spicy fish meaty aroma. Various compounds in the neutral fraction are thought to contribute to the fishy odor of Katsuobushi and a softening of the medicinal odors of the phenolic compounds.

Figure 1 shows a gas chromatogram of the neutral fraction obtained from the FID circuit. Because of the complexity of the chromatogram, the neutral fraction was further separated into ten sub-fractions by silica gel column chromatography (see Table I). All these sub-fractions were then analyzed by GC and GC-MS.

Table II lists the odor characteristics of these sub-fractions. Though the individual sub-fractions were inferior in odor to the original neutral fraction, the four sub-fractions from No. 2 to No. 5 were considered to be more important to the fish meaty and spicy aroma of Katsuobushi judging from their odors. However, the results of sniffing the effluents at the exit port of the gas chromatograph revealed the absence of an individual flavor compound having a characteristic Katsuobushi meat-like aroma in these four

TABle II. Odor Characteristics OF Sub-Fractions

\begin{tabular}{|c|c|c|}
\hline $\begin{array}{l}\text { Sub-fraction } \\
\text { No. }\end{array}$ & Odor & Main compounds identified \\
\hline No. 1 & Petroleum-like & Hydrocarbons \\
\hline No. 2 & $\begin{array}{l}\text { Fish meaty, somewhat } \\
\text { dried small } \\
\text { sardine-like }\end{array}$ & $\begin{array}{l}\text { Alkanals, aromatic ketones, } \\
\text { benzaldehyde, benzonitrile, } \\
\text { safrole, isosafrole }\end{array}$ \\
\hline No. 3 & $\begin{array}{l}\text { Spicy, vegetable-like, } \\
\text { somewhat oily }\end{array}$ & $\begin{array}{l}\text { Alkanones, alkenals, } \\
\text { camphor, acetophenone }\end{array}$ \\
\hline No. 4 & Lasting spicy & $\begin{array}{l}\text { Alkadienals, alkenols, } \\
\text { dimethoxybenzenes }\end{array}$ \\
\hline No. 5 & $\begin{array}{l}\text { Sweet fruity, somewhat } \\
\text { meaty and green }\end{array}$ & $\begin{array}{l}\text { 1-Alken-3-ols, } \\
\text { cis-1,5-octadien-3-ol, } \\
\text { cis,cis-1,5,8-undecatrien-3-ol, } \\
\text { trimethoxybenzenes }\end{array}$ \\
\hline No. 6 & Sweet, green & $\begin{array}{l}\text { Alkanols, alkenols } \\
\alpha \text {-terpineol }\end{array}$ \\
\hline No. 7 & Sweet, somewhat green & $\begin{array}{l}\text { Alkanols, alkenols, } \\
\text { 2-cyclopentenones, } \gamma \text {-lactones } \\
\text { furfurylalcohol }\end{array}$ \\
\hline No. $8 \sim$ No. 10 & Oily & Not investigated \\
\hline
\end{tabular}




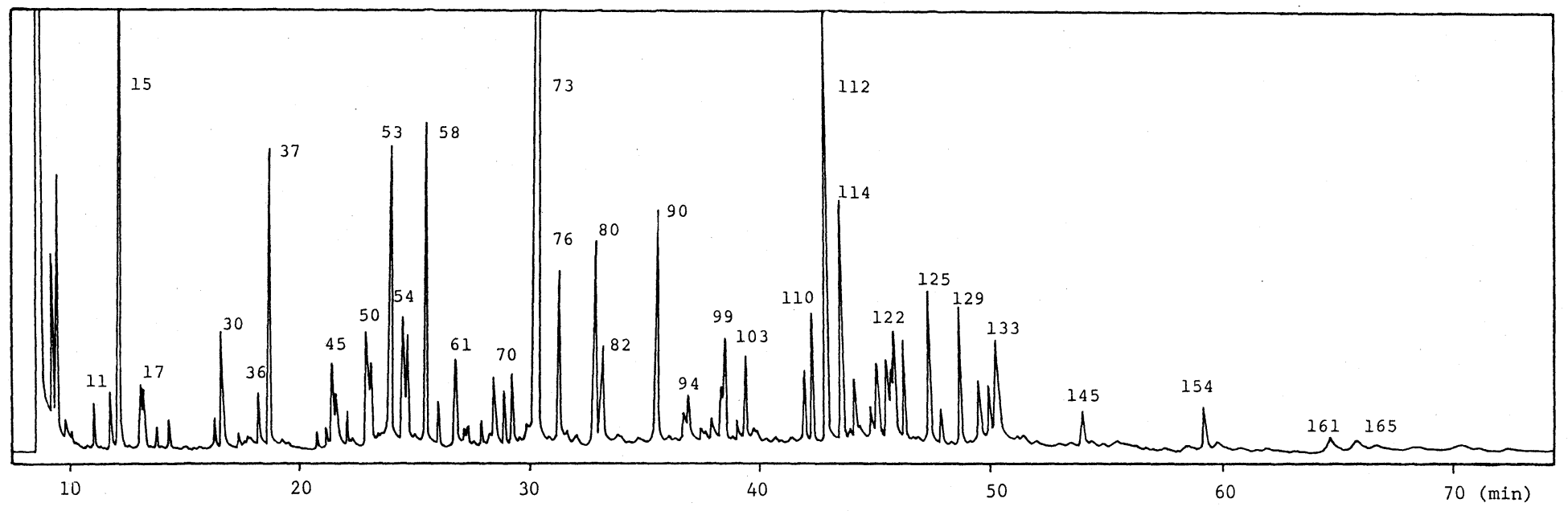

FIG. 1. Gas Chromatogram of the Neutral Fraction Detected with an FID.

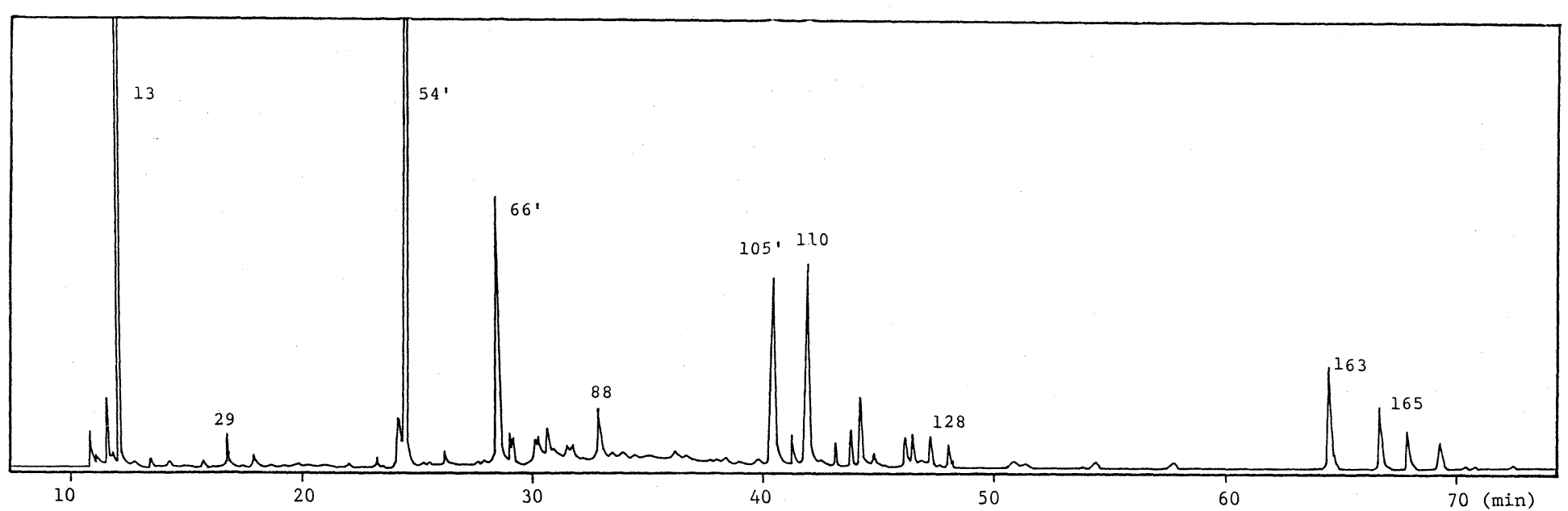

Fig. 2. Gas Chromatogram of the Neutral Fraction Detected with an FTD. 
Table III. Volatile Flavor Compounds Identified from the Neutral Fraction

\begin{tabular}{|c|c|c|c|}
\hline Peak No. & Compounds & Peak No. & Compounds \\
\hline & Hydrocarbons & $78^{*}$ & Borneol \\
\hline $4^{*}$ & Decane & $87^{\prime}$ & cis-1,5-Undecadien-3-ol \\
\hline 8 & Toluene & $95^{\prime}$ & cis,cis-1,5,8-Undecatrien-3-ol \\
\hline $12 *$ & Undecane & $96^{\prime *}$ & $p$-Cymen-8-ol \\
\hline 19 & Dodecane & 97 & Benzyl alcohol \\
\hline $29^{*}$ & Tridecane & 103 & Phenethyl alcohol \\
\hline 42 & Tetradecane & $123^{*}$ & $\beta$-Elemol \\
\hline $51^{*}$ & Indene & $126^{*}$ & Cedrol \\
\hline 55 & Pentadecane & $141^{*}$ & $\alpha$-Cadinol \\
\hline 61 & Methylindene $^{t_{1}}$ & & \\
\hline 65 & Methylindene $^{t_{1}}$ & & Aldehydes \\
\hline 68 & Hexadecane & $4^{\prime}$ & 3-Methylbutanal \\
\hline 80 & Heptadecane & 5 & Pentanal \\
\hline 83 & Naphthalene & $11^{\prime}$ & Hexanal \\
\hline 87 & $\delta$-Cadinene & $15^{\prime *}$ & trans-2-Pentenal \\
\hline 94 & Octadecane & $17^{*}$ & Heptanal \\
\hline $95^{*}$ & Calamenene & $18^{\prime *}$ & trans-2-Hexenal \\
\hline 96 & 1-Methylnaphthalene & 22 & cis-4-Heptenal \\
\hline 100 & 2-Methylnaphthalene & 28 & Octanal \\
\hline 105 & Nonadecane & $38^{\prime *}$ & Nonanal \\
\hline $112^{*}$ & Diphenyl & $44^{*}$ & trans-2-Octenal \\
\hline 115 & Eicosane & $47^{*}$ & trans,cis-2,4-Heptadienal \\
\hline 127 & Heneicosane & $49^{*}$ & trans,trans-2,4-Heptadienal \\
\hline 142 & Docosane & $53^{\prime *}$ & Decanal \\
\hline $153^{*}$ & Tricosane & 54 & Benzaldehyde \\
\hline $160^{*}$ & Tetracosane & $57 *$ & trans-2-Nonenal \\
\hline $170^{*}$ & Pentacosane & 63 & 2,4-Octadienal ${ }^{t}$ \\
\hline $186^{*}$ & Hexacosane & 63 & 2,6-Nonadienal ${ }^{\mathrm{t}}$ \\
\hline $190^{*}$ & Heptacosane & 64 & Octadienal $^{t_{1}}$ \\
\hline $192^{*}$ & Octacosane & $67^{* *}$ & 4-Methylbenzaldehyde \\
\hline \multirow[t]{3}{*}{$193 *$} & Nonacosane & $70^{*}$ & Phenylacetaldehyde \\
\hline & & $86^{*}$ & trans,cis-2,4-Decadienal \\
\hline & Alcohols & $88^{*}$ & 4-Isopropylbenzaldehyde \\
\hline $4^{\prime}$ & Ethanol & $92 *$ & trans,trans-2,4-decadienal \\
\hline $6^{*}$ & 2-Butanol & $113 *$ & Cinnamaldehyde \\
\hline 11 & 2-Methylbutan-1-ol & $131 *$ & Hexadecanal \\
\hline 14 & 1-Butanol & & \\
\hline 15 & 1-Penten-3-ol & & Ketones \\
\hline 18 & 3-Methylbutan-1-ol & $8^{\prime}$ & 2,3-Pentanedione \\
\hline 23 & 1-Pentanol & $16^{*}$ & Cyclopentanone \\
\hline $29^{\prime *}$ & trans-2-Penten-1-ol & $16^{\prime}$ & 2-Heptanone \\
\hline $29^{\prime}$ & Cyclopentanol & $18^{\prime *}$ & 2-Methylcyclopentan-1-one \\
\hline 30 & cis-2-Penten-3-ol & $19^{\prime *}$ & 3-Methylcyclopentan-1-one \\
\hline 34 & 1-Hexanol & $24 *$ & 3-Octanone \\
\hline $38^{*}$ & 3-Octanol & 27 & 2-Octanone \\
\hline $41^{*}$ & trans-2-Hexen-1-ol & $28^{\prime *}$ & Cyclohexanone \\
\hline 46 & 1-Octen-3-ol & $34^{\prime *}$ & 5-Methyl-2-cyclopenten-1-one \\
\hline $46^{\prime *}$ & 1-Heptanol & $35^{*}$ & 2,5-Dimethyl-2-cyclopenten-1-one \\
\hline $52^{*}$ & cis-1,5-Octadien-3-ol & $35^{\prime *}$ & 6-Methyl-5-hepten-2-one \\
\hline $53^{*}$ & 2-Hexanol & $36^{*}$ & 4-Methyl-2-cyclopenten-1-one \\
\hline $58^{\prime *}$ & Linalool & $36^{\prime *}$ & 2,4-Dimethyl-2-cyclopenten-1-one \\
\hline $63^{*}$ & 2-Hydroxy- $\alpha$-phenethylalcohol & 37 & 2-Cyclopenten-1-one \\
\hline $66^{*}$ & 4-Heptanol & $37^{\prime}$ & 2-Methyl-2-cyclopenten-1-one \\
\hline $67^{*}$ & trans-2-Octen-1-ol & $38^{\prime *}$ & 2-Nonanone \\
\hline $77 *$ & $\alpha$-Terpineol & $43 *$ & 2-Cyclohexen-1-one \\
\hline
\end{tabular}


TABLE III (continued)

\begin{tabular}{|c|c|c|c|}
\hline Peak No. & Compounds & Peak No. & Compounds \\
\hline $47^{\prime}$ & Dimethyl-2-cyclopenten-1-one ${ }^{t}$ & & Esters \\
\hline $48^{*}$ & 2-Methyl-2-cyclohexen-1-one & $2 *$ & Ethyl formate \\
\hline $48^{\prime *}$ & 3,4-Dimethyl-2-cyclopenten-1-one & 3 & Ethyl acetate \\
\hline $49^{\prime *}$ & 2-Decanone & $67^{\prime *}$ & Methyl benzoate \\
\hline $51^{\prime}$ & 3-Methyl-2-cyclopenten-1-one & $79 *$ & Methyl $o$-toluate \\
\hline $53^{\prime *}$ & Camphor & $80^{\prime *}$ & Methyl $p$-toluate \\
\hline $54^{\prime}$ & 2,3-Dimethyl-2-cyclopenten-1-one & & \\
\hline $58^{*}$ & 2,3,4-Trimethyl-2-cyclopenten-1-one & & Lactones \\
\hline $59 *$ & 3-Methyl-2-cyclohexen-1-one & $88^{\prime *}$ & 2,3-Dimethyl-2-buten-4-olide \\
\hline $65^{\prime}$ & 2-Undecanone & $90^{*} *$ & 2,3-Dimethyl-2-penten-4-olide \\
\hline $71^{*}$ & Acetophenone & $100^{\prime *}$ & 2,3-Dimethyl-2-hexen-4-olide \\
\hline $74^{*}$ & 2-Methylacetophenone & $107^{\prime *}$ & 3-Methyl-4-butanolide \\
\hline $80^{\prime *}$ & Propiophenone & $111^{*}$ & 2,3-Dimethyl-2-hepten-4-olide \\
\hline $87^{\prime *}$ & 4-Methylacetophenone & $115^{\prime *}$ & 4-Decanolide \\
\hline 89 & 2-Hydroxy-3-methyl-2-cyclopenten-1-one & $132 *$ & 2,3-Dimethyl-2-nonen-4-olide \\
\hline $92^{\prime *}$ & 2,4-Dimethylacetophenone & & \\
\hline $93 *$ & 4-Methylpropiophenone & & Furans \\
\hline $96^{\prime *}$ & Geranyl acetone & $23^{\prime *}$ & 2-Methyltetrahydrofuran-3-one \\
\hline $104 *$ & 4-Isopropylacetophenone & $46^{\prime}$ & Furfural \\
\hline 107 & Methylindanone $^{t_{1}}$ & $53^{\prime *}$ & 2-Acetylfuran \\
\hline $112^{\prime *}$ & 1-Indanone & $53^{\prime *}$ & Benzofuran \\
\hline $117^{*}$ & 2-Pentadecanone & $54^{\prime *}$ & Furfuryl acetate \\
\hline \multirow[t]{3}{*}{$128^{*}$} & 2-Hexadecanone & $61^{\prime *}$ & Methyl furoate \\
\hline & & $64^{\prime *}$ & 2-Methylbenzofuran \\
\hline & Ethers & 66 & 4 (or 5 , or 6 )-Methylbenzofuran ${ }^{t_{1}}$ \\
\hline $19^{\prime *}$ & 1,8-Cineol & $67^{\prime *}$ & 2-Acethyl-5-methylfuran \\
\hline 47 & 1-Methoxy-3-methylbenzene & 73 & Furfuryl alcohol \\
\hline $80^{\prime}$ & 1,2-Dimethoxybenzene & $75^{*}$ & Dimethylbenzofuran $^{t_{1}}$ \\
\hline 90 & 1,2-Dimethoxy-4-methylbenzene & $77^{\prime *}$ & 2-Ethylbenzofuran \\
\hline $92^{\prime *}$ & 1-Methoxy-4-propylbenzene & 78 & Dimethylbenzofuran ${ }^{t_{1}}$ \\
\hline $98^{*}$ & Safrole & 78 & Dimethylbenzofuran $^{t_{1}}$ \\
\hline 99 & 1,2-Dimethoxy-4-ethylbenzene & 79 & Dimethylbenzofuran $^{t_{1}}$ \\
\hline 108 & 1,2-Dimethoxy-4-propylbenzene & & \\
\hline 109 & 1,2,3-Trimethoxybenzene & & Nitrogen Compounds \\
\hline $117^{*}$ & Isosafrole & $13^{*}$ & 4-Methylpentanenitrile \\
\hline $119^{*}$ & 1,2-Dimethoxy-4-vinylbenzene & $54^{\prime *}$ & Pyrrole \\
\hline $120 *$ & 1,2,3-Trimethoxy-5-methylbenzene & $66^{\prime *}$ & Benzonitrile \\
\hline $125^{*}$ & 1,2,3-Trimethoxy-5-ethylbenzene & $105^{\prime *}$ & Phenylacetonitrile \\
\hline $133^{*}$ & 1,2,3-Trimethoxy-5-propylbenzene & 110 & 2-Acethylpyrrole \\
\hline $135^{*}$ & 2-Methoxynaphthalene & $163^{*}$ & Indole \\
\hline $142^{\prime *}$ & 1,2,3-Trimethoxy-5-(1-propenyl)benzene & $165^{*}$ & Skatole \\
\hline $145^{*}$ & 1,2,3-Trimethoxy-5-vinylbenzene & & \\
\hline
\end{tabular}

* Newly identified.

$t, t_{1}$ Tentatively identified. ( $t_{1}$ : the position of the side chain or double bond was not clear.) Overlapping peaks in Fig. 1.

sub-fractions.

The sub-fractions from No. 2 to No. 5 amounted in total to about $70 \%$ of the original neutral fraction and consisted mainly of aliphatic aldehydes, aliphatic and aromatic ketones and methoxybenzenes.

The original neutral fraction was also sub- jected to gas chromatographic analysis, using the FTD and FPD circuits, in order to identify nitrogen compounds and sulfur-containing compounds, respectively. The resulting chromatogram, using the FTD, indicates the presence of many nitrogen compounds as shown in Fig. 2. Among these, the compounds cor- 
responding to peak No. 13 , No. $54^{\prime}$, No. 66 , No. 105', No. 110, No. 163 and No. 165 were identified as 4-methylpentanenitrile, pyrrole, benzonitrile, phenylacetonitrile, 2-acetylpyrrole, indole and skatole, respectively.

On the other hand, some sulfur-containing compounds could be detected on the FPD chromatogram, but these compounds could not be identified because of their trace quantities.

Table III lists the compounds identified from the neutral fraction of the whole flavor concentrate. One hundred and sixty-five compounds were identified and 12 compounds were tentatively identified, of which 111 compounds were identified from Katsuobushi for the first time.

Various volatile aliphatic aldehydes and ketones have been found in heat-processed herring, oxidized salmon oil ${ }^{2 \sim 4)}$ and oxidized milk fat. $^{5)}$ Therefore, most of the aliphatic aldehydes and aliphatic ketones in Table II are thought to have been formed by the oxidation of lipids and fatty acids and by the degradation of amino acids during the Katsuobushi manufacturing process.

As can be seen from Table III, eleven 2cyclopenten-1-one homologues were identified, all of which have been known as wood smoke flavor components. ${ }^{6 \sim 9)}$ Therefore, most of these compounds identified from the neutral fraction are thought to have come from the wood smoke used during the Katsuobushi smoking process.

Seven $\gamma$-lactones, having faintly sweet aromatic odors, 7 alkyl phenyl ketone compounds, having harshly sweet and floral odors, and 13 methoxybenzene derivatives, having sweet vanilla-like and woody odors, were also found in the neutral fraction. These compounds seemed to be important to the warm spicy and sweet odor of the neutral fraction.

2,3-Dimethyl-2-butenolide, 2,3-dimethyl2-penten-4-olide, acetophenone, 4-methyl- acetophenone, 1,2-dimethoxybenzene, 1,2dimethoxy-4-methylbenzene and 1,2-dimethoxy-4-ethylbenzene have also been known as wood smoke flavor components, ${ }^{7,9)}$ and therefore, some of the $\gamma$-lactones, alkyl phenyl ketones and methoxybenzenes identified from the neutral fraction are thought to have come from the wood smoke.

On the other hand, Kim et al. ${ }^{10)}$ have reported that 1,2-dimethoxy-4-methylbenzene and 1,2-dimethoxy-4-ethylbenzene were considered to have been formed by methylation of 4-methylguaiacol and 4-ethylguaiacol during the molding process of Katsuobushi, because the amounts of 4-methylguaiacol and 4-ethylguaiacol decreased and 1,2-dimethoxy-4methylbenzene and 1,2-dimethoxy 4-ethylbenzene increased remarkably during the molding process.

Further detailed experiments are necessary in order to confirm the microbial formation of other methoxybenzenes identified in this study, although the phenolic compounds corresponding to the precursors of several identified methoxybenzenes have already been identified from the phenolic fraction in our previous study. ${ }^{1)}$

\section{REFERENCES}

1) I. Yajima, M. Nakamura, H. Sakakibara, T. Yanai and K. Hayashi, Agric. Biol. Chem., 45, 2761 (1981).

2) T. C. Yu, E. A. Day and R. O. Sinnhuber, J. Food Sci., 26, 192 (1961).

3) R. B. Hughes, J. Sci. Food Agric., 12, 822 (1961).

4) R. B. Hughes, J. Sci. Food Agric., 14, 893 (1963).

5) J. E. Kinsella, Chem. Ind., 2, 36 (1969).

6) W. Fidder, R. C. Doerr and A. E. Wasserman, J. Agric. Food Chem., 18, 310 (1970).

7) D. E. Hruza, Sr., M. van Praag and H. Heinsohn, Jr., J. Agric. Food Chem., 22, 123 (1974).

8) M. Fujimaki, K. Kim and T. Kurata, Agric. Biol. Chem., 38, 45 (1974).

9) K. Kim, T. Kurata and M. Fujimaki, Agric. Biol. Chem., 38, 53 (1974).

10) K. Kim, T. Yamanishi, Y. Nakatani and T. Matsui, Nippon Nôgeikagaku Kaishi, 45, 328 (1971). 